\title{
CONSIDERAÇÕES ACERCA DA RELAÇÃO ENTRE NIILISMO, MODERNIDADE E TÉCNICA NA ÉTICA JONASIANA
}

\author{
João Batista Farias Júnior \\ Graduando em Filosofia pela Universidade Federal do Piauí - UFPI
}

\begin{abstract}
RESUMO
O estudo visa analisar a conexão que Jonas estabelece entre o clima moral niilista de nossa época, a modernidade filosófica e o uso intensivo da tecnociência que lhe é associada, como pano de fundo necessário para entendermos o lugar que ele atribui à responsabilidade como princípio ético fundamental. O propósito é buscar identificar os possíveis enfrentamentos do princípio responsabilidade com a sociedade técnica moderna, na qual o niilismo passivo está inserido, tornando frágeis as bases para instalação de um princípio norteador da ação que se proponha a ser válido universalmente.
\end{abstract}

Palavras-Chave: Niilismo, modernidade, técnica, Hans Jonas, ética da responsabilidade.

ABSTRACT: This study aims to analyze the connection that Jonas sets between the nihilistic moral paradigm of our time, the modernity and the intensive use of techno-science which is associated with it, as the background necessary to understand the role of responsibility as a fundamental ethical principle. The purpose is to identify the possible confrontations of the imperative of responsibility with modern technical society, in which the passive nihilism is inserted, turning fragile the foundations for the installation of a guiding principle of action that is proposed to be universally valid.

Key-words: Nihilism, modernity, technology, Hans Jonas, ethic of responsibility.

Introdução

O pensamento de Hans Jonas (1903-1993) aparece-nos atualmente como uma grande crítica a um tempo em que a razão não se mostrou tão reflexiva, mas calculista e técnica. A modernidade e o seu alto desenvolvimento técnico se mostraram bastante compassivos com a instalação de uma terrível crise para a ética. E é a partir desta crise que se dá a proposta de Hans Jonas de uma nova ética para a atual sociedade técnicocientífica.

Jonas em sua obra mais importante, O Princípio Responsabilidade, busca repensar a relação ser e dever levando em consideração o estado crítico da natureza humana na modernidade, em que o sujeito está perdido diante de um subjetivismo de valores (JONAS, 2006). Assim, Hans Jonas nos propõe uma questão fundamental para a 
superação da crise da qual se fala e para uma retomada da relação ser e dever, agora em um âmbito mais condizente com a vida em seu sentido amplo, abrangendo todos, inclusive aqueles que ainda não são. Tal questão, ou melhor, proposta, é uma teoria ética baseada no conceito de responsabilidade.

Nossa investigação aqui visa salientar três conceitos importantes para a compreensão da obra mestra de Jonas, são eles niilismo, modernidade e técnica. Os três se relacionam no pensamento de Jonas a partir da conexão que este estabelece entre o clima moral niilista de nossa época, a modernidade filosófica, e o uso intensivo da tecnociência que lhe é associada. A partir do estudo e elucidação do vínculo entre tais conceitos, partiremos para um estudo dos limites e aplicação da ética jonasiana.

A modernidade enfrenta muitas mudanças e entre elas, no que condiz à ética, podemos dizer que o homem é aquele que perde o sensor moral que o mantinha atento sobre os perigos de suas ações. Assim, hodiernamente os indivíduos arriscam-se em atos, cujos impactos, nenhuma ciência pode realmente prever. "O mais importante que devemos reconhecer, é a realidade transformadora do homem e seu trato com o mundo, incluindo a ameaça de sua existência futura" (JONAS, 2005, p. 349). O homem em sua história cuidou de se tornar o centro de tudo, de sua arte, sua religião, suas ações e filosofia. E não apenas o homem pode ser entendido como o centro de seu fazer filosófico e científico, mas o indivíduo em suas características atuais e que desconsidera o futuro e suas gerações. A humanidade e sua ideia de grandeza fizeram-se distinguir da natureza e deixaram esta na condição de um produto disponível para seu bel prazer.

Faz-se necessária uma ética voltada para o ser, para sua conservação e para sua natureza. "Ser é necessário existir, e para existir é necessário viver e ter deveres, porém, (...) somente uma ética fundada na amplitude do ser pode ter significado" (JONAS, 2006, p. 17).

Destarte, iremos avaliar junto ao projeto de Jonas, a conjuntura em que se encontra atualmente a sociedade contemporânea, a fim de avaliar as possibilidades e os enfrentamentos de uma ética que se queira válida universalmente, a teoria ética da responsabilidade como princípio.

O problema da técnica e relação desta com a ética 
Como foi afirmado na introdução, Hans Jonas propõe uma ética que surge a partir da radicalização da técnica moderna. Em sua investigação, Jonas dá continuidade a uma ideia que é própria do pensamento de Martin Heidegger em vários de seus escritos e conferências: a mudança da essência da técnica e a relação da humanidade com a tecnologia. E nessa herança heideggeriana no pensamento de Hans Jonas temos a distinção feita entre a técnica moderna e a técnica nos tempos da Grécia antiga. É para o eco dessa transformação da técnica, de sua potencialização, que é sentido no agir humano, no domínio do homem sobre a natureza e sobre seus semelhantes, que nos chama atenção Jonas. Prometeu está não só desacorrentado, como também sem uma máxima ética que o impeça de utilizar-se da técnica para o mal. Assim, "a promessa da técnica moderna se converteu em ameaça", e é Hans Jonas quem se propõe ultrapassar esse problema e alcançar o princípio supressor da possibilidade de um mau uso da técnica. Wellistony Viana, estudioso de Hans Jonas, comenta sobre isso:

A ameaça da técnica advém do fato de que o novo poder do Sujeito não foi acompanhado por uma nova sabedoria capaz de gerar também um novo comportamento. (...) A técnica moderna representa para Jonas uma nova 'caixa de pandora' de onde saem gift (em inglês: presente), seja gift (em alemão: veneno), constituindo-se uma ameaça para a humanidade. (VIANA, 2010, p. 110).

A evidência da contribuição de Jonas é ainda maior quando vemos quão poucos atentaram para a questão da técnica tornar-se 'meio para os fins extrativistas e capitalistas da natureza' e para a exploração da natureza sem uma reflexão sobre os limites e a possibilidade daquela renovar-se. "Se antes da revolução industrial, a técnica era um tributo prestado à necessidade, agora é a mais significativa tarefa humana. (...) A técnica antes um simples meio, passa a ser, como moderna tecnologia, a própria finalidade.” (ALENCASTRO, 2007, p.17).

Dito que a preocupação de Jonas está fundamentalmente ligada à técnica, somos levados então a concluir junto de seu pensamento e cuidado para com a ética nesses novos tempos que, se a "ética tem a ver com o agir, a consequência lógica disso é que a natureza modificada do agir humano [pela ciência e tecnologia] também impõe uma modificação na ética.” (JONAS, 2006, p.29). Destarte, Jonas estabelece a chamada para um cuidado, uma atenção, uma reflexão, em seus termos, um princípio em que a 
responsabilidade renove os antigos preceitos da ética e, assim, mantenha segura a possibilidade da existência.

\section{Paradigmas do "eu" na modernidade}

Jonas, em sua investigação, salienta o caráter duplo do movimento no qual a técnica está fundada, são eles a potencialização do sujeito e a desvalorização da Natureza. A técnica moderna e essa potencialização do sujeito, muito bem desenvolvida por aqueles pensadores modernos que, crentes no poder da razão levaram o sujeito a seu mais alto grau de subjetivação, ao potencializarem o sujeito deixaram a natureza em uma condição de disponibilidade, desvalorizada.

Nesse processo em que o sujeito se vê em sua forma mais avançada, em que o espírito é absoluto e contém em si até mesmo o mundo natural, temos a história do ocidente, a história do esquecimento da natureza, da redução do Ser a entes. Heidegger pode ser visto como aquele que nos alertara do "esquecimento do ser pela metafísica", que nos falou de uma desconsideração do homem para com a natureza e da supremacia dos dispositivos técnicos. Hans Jonas, com a herança de seu mestre, trará então o questionamento sobre as consequências de tais acontecimentos, e nos propõe uma volta à objetividade do sujeito, bem como uma "revalorização da natureza". (VIANA, 2010, p.107).

Essa é a chave da conceitualização da modernidade que faz Jonas. $\mathrm{O}$ "eu" foi a grande descoberta dos modernos, e com isto temos "um movimento metafísico que passa da categoria da Objetividade dos medievais para a categoria da Subjetividade dos modernos" (Ibid., p.108). Nessa passagem temos o ponto primordial para entendermos a diferenciação do eu objetivo clássico-medieval de um eu subjetivo moderno. Este 'eu' absoluto, "não será mais um ente passivo na produção do conhecimento" (Ibid., p.108). Mas antes, será a fonte de todo o conhecimento e da moral. E então, vemos a natureza ser esquecida pela metafísica ocidental na história do Ser. Temos aí uma outra revelação, a técnica moderna se impõe como uma nova metafísica, "uma metafísica realizada, coisificada" (Ibid., p.109).

A respeito de como o princípio responsabilidade orientará o "eu" na modernidade tecnológica, a fim de garantir a possibilidade de existência da vida tal como é atualmente com suas condições, Jonas aponta para a base ontológica de seu 
fundamento para responder sobre tal garantia. A responsabilidade será o fundamento pelo qual o homem resgatará sua natureza, bem como seu papel de sujeito ético. Podendo assim superar aquilo que chamamos de objetivação do homem e desvalorização da natureza, esse niilismo tecnológico.

A crescente vontade de superação da ciência dotou-nos de aparatos técnicos incríveis, e mais, trouxe-nos a ideia de que no desenvolvimento científico estaria a vocação desse "eu" moderno. Sobre isso diz Jonas: "Somos tentados a crer que a vocação dos homens se encontra no contínuo progresso desse empreendimento, superando-se sempre a si mesmo, rumo a feitos cada vez maiores" (JONAS, 2006, p.43).

Como foi dito, a natureza foi esquecida pelos modernos. A grande preocupação do período foi o sujeito e o progresso que era direito deste. Assim, a natureza não fazia parte do escopo da responsabilidade, muito menos o imperativo de continuidade da natureza humana como bem necessário para preservação desta. O homem desassociouse daquilo que é fundamental para si, daí segue-se porque deparamo-nos, hodiernamente, com uma crise ecológica. A potencialização do sujeito firmou-se com a efetiva desvalorização da natureza, fez-se notar, então, o domínio e sujeição da natureza como princípios básicos a serem seguidos. E é com o rápido desenvolvimento da ciência que ocorreu desde então, que a modernidade abriu espaço para um desenfreado ideal de progresso.

\section{Crítica à modernidade e suas utopias}

Hans Jonas no Princípio Responsabilidade tece ainda uma crítica à modernidade e seus ideais utópicos que merece nossa atenção. Nosso filósofo desenvolve sua ética justificando-a no fato de que não devemos pôr em risco a possibilidade de existência da vida humana futura. Tal risco cresceu junto ao desenvolvimento técnico, e, hodiernamente, encontra-se em um nível devastador.

O ideal baconiano de que "saber é poder" impulsionou fortemente a ciência e esta, aliada à técnica, adotou não apenas tal lema, mas a partir dele erigiu o núcleo ideário da modernidade: o progresso.

Pouco a pouco se popularizou a ideia de que a conquista, o avanço científico, ou seja, o progresso era o destino humano. Ao homem cabia apropriar-se da natureza e, com seus conhecimentos, utilizá-la a favor da elevação da vida, da melhoria e 
perspicácia humana. Jonas, no entanto, critica o ponto ao qual chegou tal vontade; esta ultrapassou todos os limites do razoável ao pôr em risco a vida. Não mais em busca de sanar uma necessidade, agora o homem busca o mais que a tecnologia tem para lhe oferecer, esquecendo-se de que muito mais necessário é garantir a continuidade da vida.

Assim, o progresso e suas obras situam-se antes sob o signo da soberba que da necessidade. A renúncia a algumas de suas promessas diz respeito ao que excede o necessário, ao passo que sua realização poderia afetar o próprio incondicionado. (JONAS, 2006, p.85).

A modernidade converteu-se em um empilhamento de projetos tecnológicos, cada um maior e mais arriscado que o anterior. Com isso construíram-se utopias; essas, enquanto motor para a liberdade e imaginação humana, segundo Jonas, representam algo bom, mas eis que na era da técnica, utopias são não só para serem sonhadas, elas devem ser superadas.

Em virtude do caráter e sua extraordinária magnitude (...) a capacidade tecnológica nos empurra para metas outrora reservadas às utopias. (...) [Mais ainda,] A inevitável dimensão 'utópica' da tecnologia moderna faz que se reduza cada vez mais a saudável distância entre os desejos cotidianos e os fins últimos (...). (FONSECA, p.203, 2011).

Hans Jonas, com seu projeto moral, lembra-nos do dever com a vida, que já é em si uma responsabilidade humana: "Nascido do perigo, esse dever clama, sobretudo, por uma ética da preservação, da preservação e da proteção, e não por uma ética do progresso e do aperfeiçoamento." (JONAS, 2006, p.232).

\section{A apropriação da técnica pelo niilismo moderno}

Da desatenção das éticas tradicionais com os novos paradigmas da modernidade, inúmeros projetos e ideias de progresso (utopias), e da aproximação do niilismo, esse hóspede que habita a Terra há tanto tempo, somados à técnica, tem-se a situação crítica da nossa era. Sobre isso diz Rossano Pecoraro: "O século XX, século do niilismo, abrese com a morte de Nietzsche e com a crise de uma razão que sucumbirá aos horrores de duas guerras mundiais, do fascismo e do nazismo, do Holocausto e de Auschwitz". (PECORARO, 2007, p. 10).

A sociedade contemporânea irrompe em seu tempo com uma crise tão forte que dentre suas características podemos evidenciar o esvaziamento de sentido, a perda das 
verdades e da certeza metafísica. O niilismo que, seguramente, não significa em si um perigo, mas que antes, traz consigo a história do ocidente, será brevemente analisado por nós. Para que compreendamos o niilismo e sua presença na obra de Jonas, faz-se obrigatório retornarmos àquele que o tomou como elemento de estudo e que o melhor descreveu, Friedrich Nietzsche.

Desfaz-se a crença na salvação divina, no que tange ao alcance de um mundo transcendente, afinal, "Deus está morto", resta-nos tão somente a ciência para nos resguardar dos perigos. O homem moderno, como que perdendo suas bases ônticas e existenciais - podemos até dizer que isso é um eco do anúncio de que "Deus está morto" - , vê-se sozinho, presente em um mundo absurdo, em que a falta de sentido circunda tudo e todos. Assim, vemos uma onda hedonista arrastar o homem para um cenário onde os atos desmedidos de uns arriscam a possibilidade de existência de outros.

Nietzsche, em cujas obras investiga a moral, dá-se conta da importância de uma "compreensão da história do Ocidente como um processo assinalado pelo advento e consumação do niilismo" (ARALDI, 1998, p. 75). O niilismo é proveniente, segundo Nietsche, da moral, existindo uma ambiguidade nessa ideia, mas, nessa mesma ambiguidade, há já os constituintes de uma necessidade para afirmação da vida.

Mas quando é suprimida a relação transcendente e o ser humano é deixado sozinho com o mundo - e consigo mesmo -, também com o mundo, restrito agora a demonstração de poder, não lhe resta outra coisa senão uma relação de poder, o domínio. (JONAS, 2005, p.237).

Assim, se não há mais um deus que nos resguarde do mal, principalmente desse que irrompe de nós mesmos, também toda moral que precise de uma base teológica vêse em ruinas e só o que prevalece é essa relação de poder que a técnica possui e que há um bom tempo nos escapou do controle. Esse é o ambiente com o qual Jonas depara-se, esse mesmo onde não há nem um deus que nos salve da morte ou de sucumbir ao niilismo, nem uma ética que ampare e proteja a humanidade. Diz Jonas:

O deus absconditus, de quem nada se pode predizer além da vontade e do poder, em seu distanciamento deixa como herança o homo absconditus um conceito do ser humano caracterizado ainda unicamente por vontade e poder, pela vontade do poder. Para esta vontade, até a natureza indiferente é antes ocasião de atividade do que objeto real. (JONAS, 2005, p.237). 
A respeito do niilismo, Jonas dedicou um capítulo inteiro no livro Princípio $V i d a$, em que o filósofo estuda as relações entre gnose, existencialismo e niilismo. Jonas afirma-nos que a compreensão do niilismo antigo o ajudou na compreensão do niilismo moderno, que teve como base o existencialismo.

Do dualismo presente no pensamento filosófico moderno e de uma divisão entre homem e mundo feita pelo gnosticismo, tem-se a separação entre o espírito e o corpo, assim como se tem a separação do ser humano com o mundo em que vive.

Um universo sem uma hierarquia interna do ser, como é o universo copernicano, deixa sem apoio ontológico os valores, e na busca por sentido e valor o eu é inteiramente rechaçado de volta a si mesmo. $\mathrm{O}$ sentido não é mais percebido na contemplação do ser objetivo, mas colocado como um ato de valor atribuído. (JONAS, 2005, p. 236).

Esses aspectos do existencialismo moderno, bem como do niilismo que é diagnosticado em seguida, são determinantes para entendermos aquele ponto que será vital para o pensamento jonasiano, a mudança na imagem que temos sobre a natureza. "A extrema contingência de nossa existência no todo priva do sentido do ser humano este todo como possível sistema de referência para a compreensão de nós mesmos." (JONAS, 2005, p.236).

Ainda sobre o paralelo que Jonas estabelece entre o gnosticismo e niilismo moderno, ele aponta para o distanciamento entre a natureza, em termos gnósticos, o cosmos, e o homem. O esvaziamento da ideia de lei (nomos) e a consequente percepção de seu desligamento do todo, trazem consequências niilistas para o gnosticismo. Se Nietzsche nos alertou para a 'morte de Deus', Jonas igualmente nos chama a atenção no Princípio Vida para o fato de que até mesmo no gnosticismo, não há qualquer divindade gnóstica ligada a nós. Portanto, não se tem mais que prestar nenhum tipo de culto aos deuses, à natureza ou ao cosmos. Tal fato só reforça o que falamos sobre o desligamento do homem em relação à natureza e da consequente desvalorização desta.

Esta desvalorização existencialista da natureza é manifestadamente um reflexo do seu esvaziamento espiritual pela ciência natural moderna, e esta possui alguma coisa em comum com o desprezo gnóstico da natureza. Nunca uma filosofia preocupou-se tão pouco com a natureza quanto o existencialismo para quem ela não conservou nenhuma dignidade. (JONAS, 2005, p. 250).

Diagnosticado isso, Jonas desenvolve no livro Princípio Vida sua ontologia que se centraliza na vida, no fenômeno da vida como algo uno, monista, e com isso, espera 
desenvolver a base metafísica que dará sustentação à sua teoria ética, deixando de lado essa deturpação da visão da vida, possibilitando agora ao homem pensar a natureza como responsabilidade sua.

Um outro ponto a ser considerado por nós, refere-se ao que o nosso filósofo adverte sobre o ideal de progresso moderno que vem a ecoar sobre o homem e sobre o processo natural da evolução. Jonas, lembrando os ganhos da evolução, nos fala de nossa capacidade de escolha entre o bem e o mal. A evolução como ocorre naturalmente nunca foi um mal, pelo contrário, ela nos legou a possibilidade de decidirmos sobre diversos pontos de nossas vidas, "no entanto, é exatamente esse elemento transcendente que está ameaçado de ser lançado também no cadinho da alquimia tecnológica, como se a condição de todo poder rever também fizesse parte daquilo que é passível de ser revisto." (JONAS, 2006, p. 80). Agora a técnica possibilita ao homem escolher não só as novas características dos novos dispositivos técnicos, mas o próprio homem tem a possibilidade de intervir em sua evolução.

A ciência e o ideal de progresso pregado na modernidade incorporaram a vida e o homem de tal forma que a técnica passou de um recurso para o homem que necessitava produzir seu sustento para um fim em si mesmo, tornando-se um elemento central para a humanidade do nosso tempo. A dinâmica cumulativa dos efeitos da técnica representa agora um perigo impensável e imprevisível e não há em nenhuma das éticas tradicionais um mandamento que nos resguarde de tal perigo. E nesses termos vemos o niilismo, que Nietzsche dizia estar contido na história do ocidente, amparar-se na técnica e na conjuntura da modernidade.

Num período da história em que a humanidade vive sob a sombra do niilismo, sem normas objetivas, a universalidade deve ser capaz de lidar com a multiplicidade de valores que emergem a cada dia; o 'princípio responsabilidade' se configura em uma confissão de uma nova e paradoxal humildade, a de que o poder humano é infinito e ao mesmo tempo insignificante diante dos próprios desdobramentos e consequências de sua aplicação. (ALENCASTRO, 2007, p. 112).

Nesses termos, a ética da responsabilidade terá consigo um aliado para o enfrentamento e superação do limite a que a ética está sujeita na sociedade moderna, a partir do desenvolvimento da obra e da enunciação de seus imperativos, como: "não ponhas em perigo a continuidade indefinida da humanidade na Terra”, teremos já o fator que influenciará o agir ético ainda que vivamos sobre a robusta sombra de um niilismo passivo, será a "heurística do medo". 
Destarte, Jonas não segue desconsiderando o niilismo, mas antes, diz-nos sobre o que é importante ressaltar. O que nos interessa é visar a responsabilidade como o fundamento que considera o todo, e esta não nos afasta do perigo, esse mesmo que ronda aqueles que se deixam consumir por um niilismo fraco, mas antes assume o perigo e relembra-nos de seu entusiasmo, esse "entusiasmo negativo" do temor, que, contudo, supera a condição passiva do niilismo. A heurística do medo não é uma chamada à passividade, mas antes uma chamada para que ajamos frente aos perigos de uma catástrofe. Tem-se a partir do medo a retomada da ética, considerando agora diversos outros fatores, tais como: a necessidade de superarmos o antropocentrismo das éticas tradicionais, o dever moral para com as gerações futuras, os perigos das buscas desenfreadas por progresso e a reconsideração da natureza como um bem a ser preservado por nossas ações morais, nossa responsabilidade com a vida e com a preservação de uma natureza humana.

\section{Considerações finais}

Hans Jonas com seu princípio de responsabilidade apresenta-se com uma proposta de superação das éticas tradicionais que não conseguiram tratar e absorver os problemas destacados aqui e que, de certa forma, limitam-nos em nosso agir. A amplitude do princípio ético jonasiano busca absorver e superar esses problemas, tornando-se muito distinta por incorporar até mesmo a conservação da vida futura no princípio norteador das ações que se pretendem como morais.

Ao nos falar da insuficiência de outros imperativos éticos, Jonas formulou não apenas um outro imperativo para a ação que os corrigisse; indo além, Jonas considerou a atenção no que sua época estava adquirindo e que sintomatiza uma doença para a humanidade, o niilismo e a técnica. A tecnologia moderna e as implicações de seu uso usurpam não só o tempo e o espaço próximos, a ação do homem encontra-se em tamanha potência que pode causar danos irreversíveis à natureza, e, consequentemente, à humanidade.

Jonas coloca nesses termos seu imperativo: "agir de tal maneira que os efeitos de tua ação não sejam destruidores da futura possibilidade de vida humana". (JONAS, 1994, p.40). Pode-se, a princípio, pensar que tal imperativo é antropocêntrico, mas as suas outras formas e a fundamentação do mesmo demonstram o contrário. A 
centralidade da ação no homem diz apenas respeito a este ser o detentor da responsabilidade para com toda a natureza, devendo então de antemão garantir a continuidade da humanidade para que esta conserve o meio ambiente.

Heidegger já havia nos falado que a técnica não é de todo um mal, mas essa nova concepção moderna da técnica, essa sim pode nos custar caro. Heidegger tomando as palavras de Hölderlin disse-nos "e onde há o perigo, é lá também que cresce o que salva" (HEIDEGGER, 2008, p. 37).

Um emblemático afresco niilista e ético-metafísico de incomparável significado, no qual ao lado do sofrimento, desespero, morte há sempre uma chance de salvação, um gesto de caridade, afeto, solidariedade. (...) Um núcleo existencial que se alçará a uma dimensão ontológicoreligiosa, exprimindo não só o niilismo que a deflagra e a atravessa, como (e principalmente) a possibilidade ética e transcendente de uma salvação. (PECORARO, 2007 p. 15-16).

Destarte, a conexão que Jonas estabelece entre niilismo, modernidade filosófica e técnica é um componente importante para se compreender a ética da responsabilidade em toda sua extensão, no sentido de podermos então partir para a identificação de alguns dos elementos constitutivos dessa deontologia fundamentada metafisicamente no princípio vida e sua conexão com a liberdade, de modo a fornecer o conceito mediador entre ser e dever ser que é fundamental para a formulação de uma ética da responsabilidade ambiental consistente, rompendo assim com o antropocentrismo, com o pensamento utópico da modernidade, com a separação homem-natureza, e mesmo com o clima de insegurança e absurdo que aparece com a ideia de niilismo.

A partir da chamada para repensarmos a ética na era tecnológica, teremos a possibilidade de pensarmos novamente a vida, incluindo agora, em nosso pensamento ético, a importância do ser frente ao não-ser, e da necessidade de que exista vida no futuro frente ao desenvolvimento técnico. Se assumirmos a responsabilidade como princípio básico, teremos, quem sabe, a possibilidade de convivermos ainda por muito tempo em paz, sob uma harmoniosa relação com a natureza.

\section{Referências Bibliográficas}

ALENCASTRO, M.S.C. A ética de Hans Jonas: alcances e limites sob uma perspectiva pluralista. Curitiba, Tese de doutorado em Meio Ambiente e Desenvolvimento, UFPR, 2007. 
ARALDI, C. L. Para uma caracterização do niilismo na obra tardia de Nietzsche. Cadernos Nietzsche, n. 5, p. 75-94, 1998.

FONSECA, L. S. G. . Hans Jonas e a crítica à utopia. In: Robinson dos Santos; Jelson

Oliveira; Lourenço Zancanaro. (Org.). Ética para a civilização tecnológica: em diálogo com Hans Jonas. Ética para a civilização tecnológica: em diálogo com Hans Jonas. 1ed. São Paulo: São Camilo, 2011, v. , p. 195-215.

HEIDEGGER, Martin. Ensaios e Conferências. Petrópolis, Vozes, 2008.

JONAS, Hans. O princípio vida. São Paulo: Vozes, 2005.

O princípio responsabilidade: ensaio de uma ética para a civilização tecnológica; tradução do original alemão: Maijane Lisboa e Luiz Barros Montez. Rio de Janeiro: Contraponto; Ed. PUC-Rio, 2006.

PECORARO, R. Niilismo. Rio de Janeiro: Jorge Zahar Editor, 2007.

VIANA, W. C. A técnica sob o "Princípio Responsabilidade" de Hans Jonas. Pensando - Revista de Filosofia. Vol. 1, n², 2010, p. 106-118. 